\title{
Partial splenic embolization through endoscopic ultrasound-guided implantation of coil as a potential technique to treat portal hypertension
}

Partial splenic embolization (PSE) through an interventional radiology procedure has been developed to manage two common complications of portal hypertension - variceal bleeding and hypersplenism [1,2]. Here, we report the first case of endoscopic ultrasound (EUS)guided PSE, which might offer an alternative technique for the prevention of recurrence of varceal bleeding and hypersplenism.
The 71-year-old Asian man was newly diagnosed with alcoholic cirrhosis and variceal bleeding. Management options were discussed, and the patient signed the agreement for endoscopic interventions. The fundic varices were first identified and treated with EUS-guided glue injection [3] ( $>$ Video 1). Next, an isolated collateral outside the gut wall in a paragastric location was treated with vascular embolization via implantation of a coil under EUS-guidance, followed by glue in- jection ( $\mathbf{F i g} \mathbf{1 a}-\mathbf{c}$ ). However, the patient developed left upper abdominal pain and fever 2 days later. Computed tomography scan revealed the location of the coil in a small branch of the splenic artery resulting in unforeseen coil embolization (-Fig.1d-f). The patient was informed about the complications of splenic infarction and agreed to be further monitored. He was discharged 2 weeks later after relief of fever and pain. During routine follow-up over 6 months,
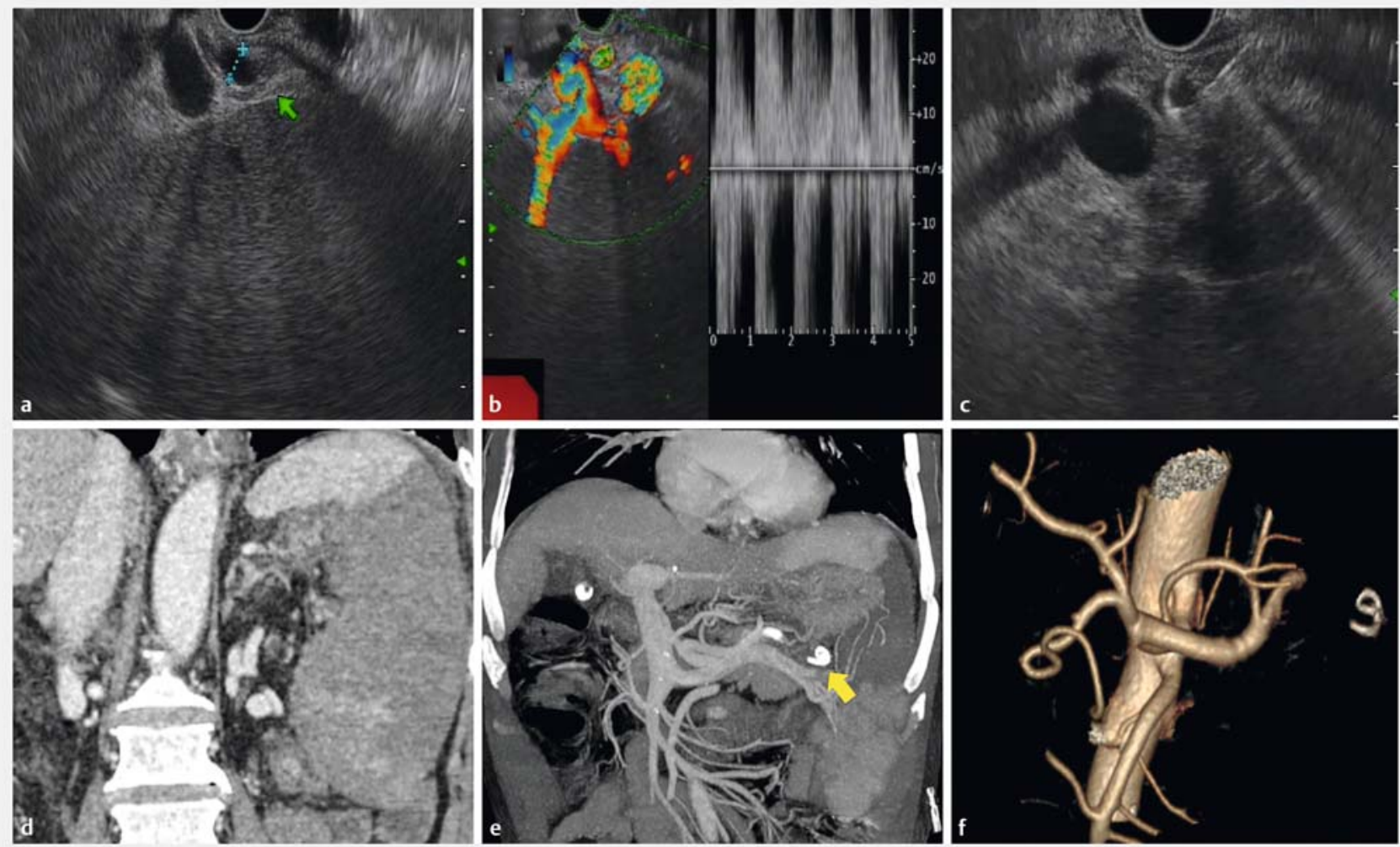

- Fig. 1 Splenic arterial embolization in a patient with varices and hypersplenism. a The targeted vessel in a paragastric location, initially thought to be an isolated collateral outside the gut wall, was re-analyzed and identified as a branch of the splenic artery. $\mathbf{b}$ Arterial flow within the vessel was confirmed using endoscopic ultrasound (EUS) color Doppler and pulsed-wave Doppler examination. c EUS-guided puncture of the targeted vessel with a 19-gauge needle and coil implantation. The coil (Nester Embolization Coil MWCE-35-5-8-NESTER; Cook Medical, Bloomington, Indiana, USA) was delivered through the needle using the stylet as a pusher. Once coiling was complete, the "sandwich method" composed of $1 \mathrm{~mL}$ lauromacrogol and $0.5 \mathrm{~mL}$ cyanoacrylate glue, was performed over 30 seconds, followed by injection of $1 \mathrm{~mL}$ saline solution to flush the glue completely through the catheter. $\mathbf{d}$, e Contrast-enhanced computed tomography scan obtained 1 day after the procedure showed infarction of more than two-thirds of the spleen (nonenhancement area) (d), and the location of the coil (e, yellow arrow). $\mathbf{f}$ Three-dimensional reconstruction displays the celiac trunk, hepatic arteries, and splenic arteries and the location of the coil, respectively. Coil with additional glue caused occlusion of the main splenic artery. 


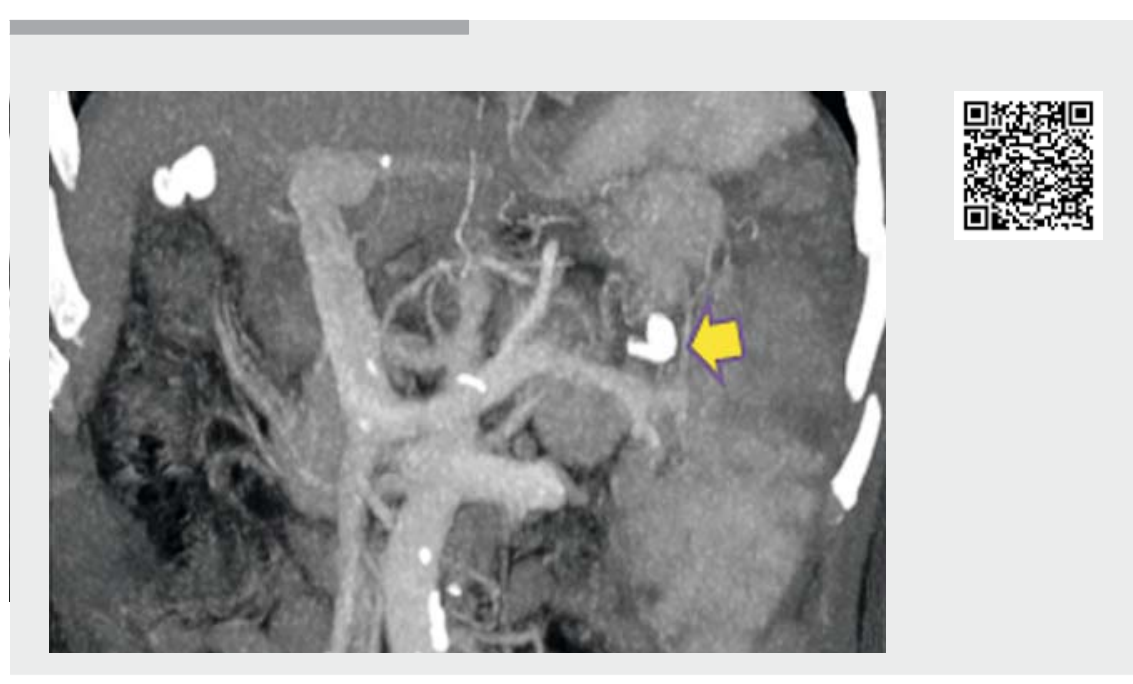

$\checkmark$ Video 1 Fundic varices were treated with endoscopic ultrasound (EUS)-guided glue injection. Splenic arterial embolization was conducted by EUS-guided coil embolization plus glue injection. Little flow was observed by Doppler indicating adequate vascular embolization.

improved hematologic parameters were observed. Diagnostic esophagogastroduodenoscopy showed reduced esophageal and gastric varices ( $\triangleright$ Video 1 ).

Key advances include: 1) PSE could be performed in parallel with conventional endoscopic interventions under EUS guidance to treat portal hypertension; 2) regarding the puncture route, the splenic artery is a branch of the celiac trunk, and passes deep to the stomach, giving rise to the left gastroepiploic artery and short gastric arteries before reaching the spleen. Therefore, direct access of branches of the splenic artery through the gastric wall appears to be a shorter approach than others and could be easily guided by EUS.

\section{Endoscopy_UCTN_Code_TTT_1AS_2AG}

\section{Acknowledgments}

This work was supported in part by grants from the National Natural Science Foundation of China (81974077).

The authors thank the patient for his engagement in this case study; informed consent was obtained from the patient for the publication of his information and imaging. Thanks also to all staff at the Endoscopy Unit of Tongji Hospital for their contributions, with special thanks to Mr. Wei Hou and Mrs. Ming Yang for assisting endoscopic procedures in this study, and to Mr. Catalin Crisan for his assistance in video editing.

\section{Competing interests}

The authors declare that they have no conflict of interest.

The authors

Qian Chen ${ }^{1,}{ }^{*}$, Zhen $\mathrm{Li}^{2,{ }^{*}}$, Yang Yang ${ }^{2}$, Wei Yan', Bin Cheng', Yue Yuan ${ }^{3}$, Zhen-gang Zhang'

1 Division of Gastroenterology, Department of Internal Medicine at Tongji Hospital, Tongji Medical College, HUST, Wuhan, China

2 Department of Radiology at Tongji Hospital, Tongji Medical College, HUST, Wuhan, China

3 Tongji Medical College, HUST, Wuhan, China

\section{Corresponding author}

\section{Zhen-gang Zhang, MD, PhD}

Division of Gastroenterology, Department of Internal Medicine at Tongji Hospital, HUST, 1095 jie Fang Avenue, Wuhan 430030, P. R. China Fax: +86-27-83663500

zhangzhg@126.com
[1] Xu RY, Liu B, Lin N. Therapeutic effects of endoscopic variceal ligation combined with partial splenic embolization for portal hypertension. World J Gastroenterol 2004; 10 : 1072-1074

[2] Koconis KG, Singh H, Soares G. Partial splenic embolization in the treatment of patients with portal hypertension: a review of the English language literature. J Vasc Interv Radiol 2007; 18: 463-481

[3] Robles-Medranda C, Oleas R, Valero M et al. Endoscopic ultrasonography-guided deployment of embolization coils and cyanoacrylate injection in gastric varices versus coiling alone: a randomized trial. Endoscopy 2020; 52: 268-275

Bibliography

Endoscopy 2021; 53: E40-E41

DOI $10.1055 / a-1174-5590$

ISSN 0013-726X

published online 29.5.2020

(c) 2020. Thieme. All rights reserved.

Georg Thieme Verlag KG, Rüdigerstraße 14,

70469 Stuttgart, Germany

\section{ENDOSCOPY E-VIDEOS}

https://eref.thieme.de/e-videos

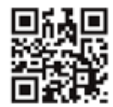

Endoscopy E-Videos is a free access online section, reporting on interesting cases and new

techniques in gastroenterological endoscopy. All papers include a high quality video and all contributions are freely accessible online.

This section has its own submission website at https://mc.manuscriptcentral.com/e-videos 